\title{
Irradiation Behavior Study of U-Mo/Al Dispersion Fuel with High Energy Xe
}

\section{B. Yea, , S. Bhattacharyab, K. Moa, D. Yuna, W. Mohameda, M. Pellind, J. Fortnerc, Y.S. Kima, G.L. Hofmana, A.M. Yacouta, T. Wiencek ${ }^{a}$, S. Van den Berghe ${ }^{e}$, A. Leenaers ${ }^{e}$}

aNuclear Engineering Division, Argonne National Laboratory, 9700 S. Cass Ave. Lemont, IL 60439, USA

bDepartment of Materials Science and Engineering, Northwestern University, 2220 Campus Dr. Evanston, IL 60208, USA

${ }^{c}$ Chemical Sciences \& Engineering Division, Argonne National Laboratory, 9700 S. Cass Ave. Lemont, IL 60439, USA

dPhysical Science and Engineering, Argonne National Laboratory, 9700 S. Cass Ave. Lemont, IL 60439, USA

eNuclear Material Science Institute, SCK·CEN, Boeretang 200, 2400 Mol, Belgium

${ }^{*}$ Corresponding author

Tel: +1 630252 4506;

Fax: +1 6302525161 ;

E-mail address: bye@anl.gov.

Submitted for publication in Journal of Nuclear Materials

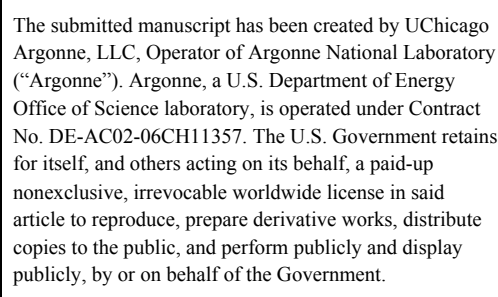




\begin{abstract}
Irradiation responses of $\mathrm{U}-\mathrm{Mo} / \mathrm{Al}$ dispersion fuel have been investigated by irradiation with 84 $\mathrm{MeV} \mathrm{Xe}^{26+}$ ions. Dispersion fuels fabricated with uncoated and $\mathrm{ZrN}$-coated fuel particles were irradiated to various doses at $\sim 350^{\circ} \mathrm{C}$. The highest dose achieved was $2.9 \times 10^{17}$ ions $/ \mathrm{cm}^{2}(\sim 1200$ displacement per atom (dpa)). Following the irradiation, scanning electron microscopy (SEM) and transmission electron microscopy (TEM) experiments were carried out to characterize the microstructures of the irradiated samples. The post irradiation examinations (PIE) revealed that: (1) crystalline interdiffusion product $(\mathrm{UMo}) \mathrm{Al}_{\mathrm{x}}$ developed at locations where no coating or compromised coating layer is present; (2) intact ZrN coating layers effectively blocked the interdiffusion between U-Mo and Al; (3) SEM-observable Xe bubbles distributed along grain/cell boundaries in U-Mo; (4) gas bubble interlinkage was observed at a dose of $2.9 \times 10^{17} \mathrm{ions} / \mathrm{cm}^{2}$.
\end{abstract}

\title{
Key words: High energy Xe ion irradiation, U-Mo/Al dispersion fuel, ZrN coating
}




\section{Introduction}

U-Mo fuels with very high uranium densities have been developed for use in high performance reactors in order to reduce the use of highly enriched uranium (HEU) fuel in the civil fuel cycle [1]. Uranium alloyed with molybdenum (Mo) possesses acceptable irradiation stability, mechanical properties and corrosion resistance [2, 3]. Although it is a promising fuel, U-Mo dispersion fuel is yet to be qualified fuel for high flux research reactors. In this form, in which U-Mo fuel particles are dispersed in an aluminum matrix, the build-up of a fuel-matrix-interaction (FMI) layer between the U-Mo fuel particle and the Al matrix limits the fuel performance [4-12]. The amorphous nature of the FMI layer $[13,14]$ results in a high fission gas mobility at high fission rates in the FMI. Undesired pillowing (plate swelling $>100 \%$ ) of the fuel plate due to the formation of large pores filled with fission gas at the interface of the FMI layer and the Al matrix has been observed in a number of in-pile tests [15-18].

Attempts have been made to improve the in-pile behavior of the low enriched U (LEU)-Mo/Al fuel system by adding Si to the Al matrix [6,9]. The RERTR-6 [6, 19, 20] and IRIS-3 [21] tests demonstrated that the addition of Si to the matrix can limit the formation of FMI [22]. However, unacceptable local swelling $[21,23]$ is still observed at the high burnup and fission rate regions. Therefore, applying a protective layer on the fuel particle surface was proposed to eliminate the interaction between the U-Mo particle and the $\mathrm{Al}$ matrix $[24,25]$. $\mathrm{ZrN}$ is chosen as a suitable coating material, because it is metallurgically inert towards both the U-Mo particle and the Al matrix [25-27]. In this out-of-pile experiment, U-Mo/Al dispersion fuel samples fabricated with uncoated U-Mo powder or ZrN-coated U-Mo powder were irradiated. The effectiveness of the $\mathrm{ZrN}$ coating was determined by comparing the behavior of these samples.

In the recent SELENIUM test, two fuel plates, one with Si coated U-Mo particles and the other with $\mathrm{ZrN}$-coated particles, were irradiated in the BR2 reactor in Belgian nuclear research center 
SCK.CEN $[28,29]$. The PIE clearly showed that no interaction of the fuel with the matrix occurred except in locations that were irradiated at high fission rates and reached a fission density of $4.5 \times 10^{21}$ fissions $/ \mathrm{cm}^{3}$ [29]. Most locations where the FMI layer had formed at high burnup were still covered with the coating layer. Additionally, although pillowing of the plates was not observed, at the high burnup regions of the plates, plate thickness showed accelerated increase. Although no definitive origin has been established yet, it is reasoned that the fission-product (both solid and gaseous)-driven swelling in U-Mo is responsible for the accelerated swelling [30]. Therefore, understanding the fission product behavior in U-Mo is critical to improve fuel performance.

In order to investigate the effectiveness of the coating layer mitigating the fission-productdriven fuel swelling behavior, a fission-fragment-energy Xe ion irradiation experiment was conducted at the Argonne Tandem Linac Accelerator System (ATLAS) at Argonne National Laboratory (ANL). U-Mo/Al dispersion fuel samples fabricated with uncoated U-Mo powder and ZrN-coated U-Mo powder were irradiated. In this study, Xe, the typical gaseous fission product, is selected as the irradiation source to emulate in-pile irradiation effects. The advantages of using ion irradiation as a surrogate for in-reactor testing are rapid accumulation of damage under controllable conditions and simple accessibility of samples as handling of highly radioactive materials is not involved. Previous studies [27, 31-35] have shown that well-controlled ion irradiation on dispersion fuels can help to understand the underlying mechanisms of dispersion fuel behavior and optimize the material matrix for in-pile tests. This paper reports the unique set up of the irradiation and preliminary PIE results obtained.

\section{Experimental}

Two miniature fuel plates $(10 \mathrm{~cm}$ (length) $\times 2.5 \mathrm{~cm}$ (width) $\times 0.14 \mathrm{~cm}$ (thickness)) were fabricated at ANL for the ATLAS irradiation. Both plates consisted of an $8 \mathrm{gU} / \mathrm{cm}^{3}$ dispersion of atomized natural $\mathrm{U}-7 \mathrm{wt} \% \mathrm{Mo}$ (denoted as $\mathrm{U}-7 \mathrm{Mo}$ ) alloy powder in a pure Al matrix. One plate 
contained U-7Mo powder coated with a layer of $1 \mu \mathrm{m}$ thick $\mathrm{ZrN}$, and the other contained un-coated U-7Mo powder. The atomized natural U-7Mo powder was provided by Korea Atomic Energy Research Institute (KAERI), and the coating layer was applied by magnetron sputtering (or physical vapor deposition (PVD)) at SCK·CEN in the STEPS\&DRUMS coater [25]. The fuel powder was mixed with aluminum powder and then pressed into a green compact. The compacts were then assembled into a 6061 aluminum alloy frame and two 6061 aluminum alloy cover plates. The cladding was metallurgically bonded by hot and cold rolling to an $80 \%$ reduction in thickness. During fabrication, the plates were heated to $500^{\circ} \mathrm{C}$ for 4 hours for hot rolling and blister testing. For the ion irradiation experiment, small disks of $1.7 \mathrm{~mm}$ diameter were punched through the thickness of the fuel plates. One side of the cladding was removed using abrasive paper (with a final polish done with $5 \mu \mathrm{m}$ paper) to get access to the fueled zone. During irradiation, the polished surface was exposed to the ion beam.

A unique multi-specimen sample holder dedicated to ATLAS ion irradiation was designed and used in the irradiation. As shown in Figure 1, there are a total of 19 mini specimen holders $(2 \mathrm{~mm}$ in diameter) within a $1 \mathrm{~cm}$ diameter area. Due to the Gaussian beam profile, the samples were exposed to four dose rates, depending on sample location (shown in Figure 2 indicated with 4 different colors). Five thermocouples are connected to the stage through the backside, as seen in Figure 1, to monitor the sample temperatures across the sample stage during irradiation. This sample stage design significantly reduced the beam time required to complete the test material matrix.

(insert Figure 1)

(insert Figure 2)

(insert Table 1) 
The irradiation was conducted with $84 \mathrm{MeV} \mathrm{Xe}^{26+}$ ions perpendicular to the sample stage surface at the ATLAS accelerator with a beam current of 43 - 108 particle nano-Ampere (pnA) for 88 hours. The beam was tuned to have a Gaussian profile with $10 \mathrm{~mm}$ full width at half maximum (FWHM) and was positioned such that the beam center was well aligned with the stage center. During irradiation, the beam spot covered all 19 specimens, which was confirmed by observing color change of silver paint applied on the stage surface. The accumulated dose received by each specimen was estimated based on the beam profile and the specimen location, and the calculated values are listed in Table 1. Note that all dpa (displacements per atom) values mentioned in this paper are the dpa at the peak damage region in the irradiation depth direction, overlapped with the Xe accumulation region.

There were 13 total specimens irradiated: 7 specimens containing ZrN-coated U-7Mo powder and 6 specimens containing un-coated U-7Mo powder. These specimens, as distributed, experienced 4 dose rates. Except for the one located at the center, all specimens containing ZrNcoated U-7Mo powder had their un-coated counterpart located at a symmetric position, so that the microstructures of these two types of specimens could be directly compared. At the time of reporting, only the specimens at the center and in Ring 1 have been examined. PIE on samples with lower doses is still on-going, and the results will be reported later on.

In this experiment, a rise in specimen temperature was caused by ion beam heating. A moderate beam current $(\leq 100 \mathrm{pnA})$ was maintained to control the specimen temperature. The temperatures of the specimens were $\leq 350^{\circ} \mathrm{C}$ during the irradiation. In order to obtain irradiation conditions comparable to in-pile irradiation (central line fuel temperature $\leq 200^{\circ} \mathrm{C}$ ), a cooling system will be added to reduce the specimen temperature in the subsequent irradiation. If an efficient cooling system is added, ion flux can be increased, so either irradiation time can be greatly reduced or the final dose level can be increased. 
According to SRIM (Stopping and Range of Ions in Matter) [36] calculations, the penetration depth of an $84 \mathrm{MeV}$ Xe ion is $\sim 6 \mu \mathrm{m}$ in $\mathrm{U}-7 \mathrm{Mo}$ and $\sim 13 \mu \mathrm{m}$ in $\mathrm{Al}$ (shown in Figure 3). For these calculations, the threshold displacement energies of $55 \mathrm{eV}, 25 \mathrm{eV}$, and $25 \mathrm{eV}$ were assumed in the U, Mo-, and Al-lattice, respectively. The choice of threshold displacement energy of U-lattice is based on the measured value of the threshold displacement energy of the Ce-sublattice in $\mathrm{CeO}_{2}$ [37] and the calculated value for $\mathrm{U}$-sublattice in $\mathrm{UO}_{2}$ [38]. The values of threshold displacement energy of Mo- and Al- lattice used in this study are default values in SRIM.

(insert Figure 3)

Following irradiation, samples for characterization were prepared in cross-section through the irradiation surface to span the full depth of the irradiation. Both focused ion beam (FIB) milling and conventional mechanical grinding methods were utilized to prepare samples for microscopy. FIB milling was performed with a FEI Helios Nanolab 600 dual-beam FIB/SEM, and conventional mechanical grinding was done at ANL. SEM observations were made either on the dual-beam FIB/SEM at Northwestern University or a Hitachi S3000N at ANL. The TEM characterization was performed with a Hitachi-9000 at the IVEM-Tandem facility at ANL.

\section{Results}

\subsection{Interdiffusion layer formation}

Figures 4 (a) and (b) show the cross section of the specimens with $\mathrm{ZrN}$-coated (Figure 4 (a)) and un-coated (Figure 4 (b)) powder irradiated to a dose of $2.6 \times 10^{17}$ ions $/ \mathrm{cm}^{2}(\sim 1100 \mathrm{dpa}$, Ring 1). Figures 4 (c) and (d) display the microstructures of as-fabricated specimens as references. Comparing the microstructures of the irradiated specimens to those of the as-fabricated specimens, 
substantial FMI growth (in light grey contrast) can be seen on the specimen surface exposed to the ion beam. In samples with uncoated particles, interaction products formed and grew onto the ionbeam-exposed U-Mo particle surface. In the samples containing coated particles, interdiffusion occurred at the edge of the U-Mo particle surface, where the coating layer was damaged during polishing to remove one side of cladding. Figure 5 is a typical top view of the specimens after irradiation. The surface roughness is mainly caused by FMI product formation at the edge of the fuel particles. The thickness of the FMI product varies with location and is in the range of a few microns.

(insert Figure 4)

(insert Figure 5)

The formation of FMI product is presumably induced by ion irradiation. Thermally-activated lattice diffusion can be excluded for the following two reasons; because no FMI is found beyond the ion damage region, and a nearly uniform temperature distribution can be reasonably assumed across the entire sample due to the high thermal conductivity of the materials $\left(\lambda_{\mathrm{Al}}=225 \mathrm{~W} /(\mathrm{m} \cdot \mathrm{K})\right.$, $\left.\lambda_{\mathrm{U}-\mathrm{Mo}_{0}}=14.2 \mathrm{~W} /(\mathrm{m} \cdot \mathrm{K})[39][39]\right)$ and the irradiation beam profile was relatively flat.

Some of the FMI layer was grown on U-Mo particle surfaces, as shown in Figure 4 (a) and (b), where there is no direct contact between U-Mo and the Al matrix. Similar phenomenon was also observed in U7Mo/Al fuel irradiated with $80 \mathrm{MeV}$ I $[40,41]$. One would wonder how U-Mo reacts with $\mathrm{Al}$ in this case. A reasonable explanation is that $\mathrm{Al}$, the most mobile species in the $\mathrm{U}-\mathrm{Mo} / \mathrm{Al}$ system, diffused onto the U-Mo surface through surface diffusion. Generally, the surface diffusion coefficient is much higher than that of lattice diffusion [42], and its diffusion mechanism allows two materials to react when lattice diffusion is restricted. This process, however, is distinct from what 
happens in in-pile tests where fission fragments come out from the fuel particles and cause U-Mo-Al interdiffusion in the bulk.

(insert Table 2)

Energy dispersive X-ray (EDX) analyses were performed at several positions in each specimen to measure the composition of FMI product. Representative results are summarized in Table 2, showing the atomic ratio of $\mathrm{Al} /(\mathrm{U}+\mathrm{Mo})$ ranges between 2.5 and 4.7 , which is similar to the $\mathrm{FMI}$ composition found in the FUTURE fuel plates [16] but lower than IRIS-1 test result [43][43]. The composition of FMI depends on the irradiation temperature, fuel loading, and burnup [43, 44][43][44]. Higher temperature normally leads to lower $\mathrm{Al} /(\mathrm{U}+\mathrm{Mo})$ ratio [45][45]. It is difficult to quantitatively correlate FMI growth with ion irradiation damage level by using the current results, due to the complex sample configuration. A simpler layered sample (an Al layer + a U-Mo layer) needs to be used in future irradiation to help understand this important aspect.

The TEM image in Figure 6 shows the microstructure of FMI region, and the inset select-areadiffraction (SAD) pattern reveals its nano-crystalline character. The nano-grains shown in Figure 6 have no preferred alignment or texture; their sizes range from $\sim 10 \mathrm{~nm}$ to $\sim 200 \mathrm{~nm}$. In order to examine if the crystalinity changes along ion penetration depth, electron diffraction patterns (Figure 7) were taken across the FMI region in the specimen irradiated to a dose of $2.9 \times 10^{17}$ ions $/ \mathrm{cm}^{2}(\sim 1200 \mathrm{dpa})$. The same crystalline structure of FMI product was obtained in similar fission fragment energy iodine irradiations before [31, 46][31] [45]. A recent experiment by Chiang et al. [27], however, reported that evidence of an amorphous FMI layer can be found in an iodine ion irradiated $\mathrm{U}-8 \mathrm{Mo} / \mathrm{Al}$ interface at $140 \pm 2^{\circ} \mathrm{C}$ at a dose of $1 \times 10^{17}$ ions $/ \mathrm{cm}^{2}$. Therefore, it is speculated that the irradiation temperature is the controlling factor in FMI product amorphization. 
Maintaining U-Mo fuel temperature below $200^{\circ} \mathrm{C}$ might be a necessity for obtaining amorphous FMI phase.

(insert Figure 6)

(insert Figure 7)

\subsection{Effectiveness of $\mathrm{ZrN}$ coating}

Characterization of ZrN-coated fuel particles at SCK.CEN showed that almost all fuel particles coated in the STEPS\&DRUMS coater are coated with a smooth and homogeneous ZrN coating layer with an average thickness of $\sim 1 \mu \mathrm{m}$ [25]. The same coating quality is expected to be on the U-Mo particles used in this experiment. However, the coating layer can be partially damaged during both plate production and the polishing process prior to ion irradiation. In plate production, the damage comes from the mechanical forces during rolling or the thermal expansion mismatch between the fuel and the coating in hot rolling-blister tests [25]. In polishing, the brittle ceramic ZrN coating layer near the surface can be broken due to grinding friction. Figure 8 shows that part of the $\operatorname{ZrN}$ coating layer is missing (arrows), and U-Mo reacts with Al to form interdiffusion products in these areas.

(insert Figure 8) 
The evidence of $\mathrm{ZrN}$ as an effective diffusion barrier is presented in Figure 9. The SEM micrograph depicts the cross section of the sample irradiated to $2.9 \times 10^{17}$ ions $/ \mathrm{cm}^{2}(\sim 1200 \mathrm{dpa})$. For U-Mo particle (A) the ZrN coating layer is intact and no FMI products are observed within the ion penetration depth. In contrast, a considerable amount of FMI products have formed on particle (B) where the coating layer is absent due to either imperfect coating or fabrication damage. The absence of FMI in particle (A) also proves that no thermally-driven interdiffusion occurred during irradiation $\left(\sim 350^{\circ} \mathrm{C}, 88\right.$ hours $)$ when the $\mathrm{ZrN}$ coating layer is present. These results appear to show that a $1 \mu \mathrm{m}$ thick $\mathrm{ZrN}$ coating would be sufficient to block the interaction between $\mathrm{Al}$ and U-Mo induced either by thermally driven diffusion at $350^{\circ} \mathrm{C}$ or by ion beam mixing. This observation is consistent with the results from $\mathrm{ZrN}$-coated $\mathrm{UMo} / \mathrm{Al}$ plate irradiated with $80 \mathrm{MeV}$ I to a dose of $1 \times 10^{17}$ ions $/ \mathrm{cm}^{2}[46]$.

(insert Figure 9)

\subsection{Xe gas bubble morphology}

One important reason for choosing Xe ions as the irradiation source is to study fission gas behavior in U-Mo fuel. Figure 10 shows the Xe bubble distribution observed on a FIBed cross section of a U-Mo particle irradiated to a dose of $2.9 \times 10^{17}$ ions $/ \mathrm{cm}^{2}(\sim 1200 \mathrm{dpa})$. The bubbles formed in a range of 4-6 $\mu \mathrm{m}$ away from the surface (Figure 10(a)). Instead of a narrow layer, the bubbles scattered in a relatively wide band compared to the SRIM prediction (Figure 3(b)). Several factors may contribute to the broadened gas bubble distribution range. The first one is that the continuous build-up of FMI products on the specimen surface extended the Xe ion projected distance in U-Mo. Another possible cause is associated with the preferred trapping power of grain boundaries. It is evident in Figure 10(b) that the gas bubbles preferably reside along the grain/cell 
boundaries. As a result, the gas bubble density is far from uniform in the Xe deposition range. In some areas, large grains without the presence of SEM-observable fission gas bubbles (white arrow) can be found; but in other areas (dark arrow), the gas bubble density is so high that no clear grain boundaries can be identified. It is suspected that grain subdivision may have occurred in the densely bubble-populated regions; this will be explored with further TEM analyses.

(insert Figure 10)

Higher-magnification SEM micrographs of the areas of interest indicated in Figure 10(a) are presented in Figure 10(c) and (d). As depicted in Figure 10(c), bubbles in the U-Mo region vary in size, from tens to hundreds of nanometers. The largest bubble likely forms at the expense of several small bubbles at a location where grain/cell boundaries intersect. Evidence of gas bubble interlinkage is clearly shown in Figure 10(c) (circled areas). It is not clear at what dose level bubbles start to interlink. PIE results on the samples irradiated to lower doses will help develop understanding of the bubble evolution process. In addition to large bubbles, lines of small gas bubbles are present in the U-Mo region. These lines align with the cellular structure formed during atomization of U-Mo particles.

\section{(Insert Figure 11)}

TEM investigation was performed to look for the nano-sized bubbles within grains. The FIB liftout shown in Figure 10(a) was further thinned down to $\sim 60 \mathrm{~nm}$ to obtain electron transparency. The bright-field (BF) TEM images in Figure 11 were taken near the area shown in Figure 10(d). Figure 11 shows that high-density gas bubbles formed within a fuel grain. Figure 11(a) is a BF 
image slightly under focus and the bubbles appear as white spots; Figure 11(b) is a BF image slightly over focus and the bubbles appear as dark spots. The average size of the intra-granular bubbles is $\sim 5 \mathrm{~nm}$ in diameter, which is larger than the reported superlattice bubble size $(\sim 3.5 \mathrm{~nm})$ in reactor-irrdiated U-Mo fuel [14]. No particular ordering of gas bubbles was confirmed in this sample. However, no definitive conclusion can be drawn on the existence of bubble superlattice under the irradiation conditions described in this paper, since the TEM observation was made in a very limited area. Further investigation will be carried out in samples irradiated to various doses.

(insert Figure 12)

When applying the same technique of changing through the focus to observe the FMI area in the same TEM specimen, no contrast changes were observed (shown in Figure 12). Therefore, no nanosize bubbles were found in the nano-crystalline FMI area. Furthermore, large gas bubble concentration decreases considerably from the U-Mo region to the FMI region, as shown in Figure $10(d)$, which indicates FMI product has poor retention of gases. It was reported that the amorphous nature of FMI product gave rise to its low viscosity for bearing stable fission gas bubble growth [13, 47][13], 0. However, the current observation also suggests that FMI product, even in crystalline structure, has very limited retainability of gases.

It is also exhibited in Figure 10(d) that most of the bubbles, residing in the FMI region and at the interface of U-Mo and FMI product, are relatively large. This microstructure is in agreement with the observation obtained on U-7Mo fuel irradiated in reactor [29]. During irradiation, it is possible that the bubbles in the FMI region formed before U-Mo reacted with Al. With the progress of the front of FMI product, most of small bubbles were swept out due to the poor gas retention of FMI. Only large bubbles survived at the end of irradiation. With this hypothesis, most of bubbles might vanish eventually if the sample was irradiated to a high enough dose. Another possible explanation 
for the existence of large bubbles at the interface of U-Mo and FMI is due to the discontinuity of phases, where the fuel-FMI interface served as the preferred sink for defects.

\section{Discussion}

The FMI products grown in the reactor environment are normally amorphous in plate-type fuels $[13,14]$, although well-crystallized $\mathrm{UAl}_{3}$ phase was also identified in pin-type U-Mo/Al fuel elements which are generally operated at higher temperatures [48][48]. However, most of the FMI products formed under heavy ion irradiation, either in this work or in previous experiments [31, 35][31] [45] performed in Garching, Germany, have a crystalline structure. Additionally, the

interdiffusion products resulting from thermal aging always appear crystalline [4953][1172841453][53]. Such comparison among the outcomes of these three types of tests indicates that temperature is the dominant factor in the crystal structure of FMI product: at low temperature $\left(<200^{\circ} \mathrm{C}\right)$, the FMI product is amorphized due to irradiation; at higher temperature, the interaction phase can recrystallize above the so called glass transition temperature even at high irradiation damage levels. The behavior of the interdiffusion phase depends on its Al content $[54,55][54][55]$.

X-ray diffraction (XRD) analyses have revealed that the interaction zone formed by thermal annealing contains both binary phases $\left(\mathrm{UAl}_{3}\right.$ and $\left.\mathrm{UAl}_{4}\right)$ and ternary phases $\left(\mathrm{U}_{6} \mathrm{Mo}_{4} \mathrm{Al}_{43}\right.$ and $\mathrm{UMo}_{2} \mathrm{Al}_{20}$ ) $[49,50][1172841453]$ [50]. By contrast, only binary phases (mainly $\mathrm{UAl}_{3}$ ) were found in the interaction product induced by $80 \mathrm{MeV}$ iodine ions. Therefore, it is of interest to obtain a fine description of phases constituting the FMI product generated in this experiment to compare with other tests. The results will shed light on how the interdiffusion process occurs.

A comparison of the ion irradiation results with reactor irradiation results was attempted. Assuming all impinging Xe ions were deposited in a $2 \mu \mathrm{m}$ thick layer, the average gas density within the deposition layer in the specimen irradiated to $2.9 \times 10^{17} \mathrm{ions} / \mathrm{cm}^{2}$ was $1.45 \times 10^{21} \mathrm{ions} / \mathrm{cm}^{3}$. It is 
known that the total fission yield of stable $\mathrm{Xe}$ and $\mathrm{Kr}$ for ${ }^{235 \mathrm{U}}$ in a power reactor fuel is around 0.25 [56][56]. To reach the same concentration of stable fission gases, the equivalent fission density is $5.8 \times 10^{21}$ fissions $/ \mathrm{cm}^{3}$. On the other hand, PIE on the U-7Mo fuel irradiated in reactor showed that at $\sim 5.0 \times 10^{21}$ fissions $/ \mathrm{cm}^{3}$, fuel particles have already been fully recrystallized [29]. The bubble morphology observed here is more similar to what is seen in the fuel irradiated to $\sim 4.5 \times 10^{21}$ fissions $/ \mathrm{cm}^{3}$. In reactor irradiation, fission gases take only a small fraction of fission products that cause irradiation damage in fuel. Hence, much more atomic displacement damage occurred in reactor irradiation than in ion irradiation corresponding to the same fission gas concentration. It is not straight forward to directly compare results from these two types of irradiations. Indeed, a small shift in one irradiation variable leads to significant changes in the aggregate behavior of defects [57-59][57][59]. The main objectives of this experiment are to investigate specific microstructural processes such as irradiation-induced FMI and gas bubble growth and to provide a reasonable indication of $\mathrm{U}-\mathrm{Mo} / \mathrm{Al}$ fuel behavior. For these applications, a well-controlled ion irradiation experiment remains valid and adequate.

\section{Conclusions}

In order to study the irradiation behavior of U-Mo/Al dispersion fuel, U-Mo/Al fuel samples were irradiated with $84 \mathrm{MeV}$ Xe ions in a specially designed multi-sample stage to doses of 1.8 $2.9 \times 10^{17}$ ions $/ \mathrm{cm}^{2}(\sim 750-1200 \mathrm{dpa})$. Irradiation-induced FMI layer formation, ZrN coating effectiveness in preventing U-Mo-Al interdiffusion, and fission gas bubble morphology were investigated. Characterizations of the irradiated samples revealed that the FMI layer composition was in accord with reactor irradiation results. However, the FMI layer remained crystalline at the dose of $2.9 \times 10^{17}$ ions $/ \mathrm{cm}^{2}(\sim 1200 \mathrm{dpa})$, which was in contrast to the amorphous nature of FMI layer grown under reactor irradiation. This difference might be due to the relatively high 
irradiation temperature $\left(\sim 350^{\circ} \mathrm{C}\right)$. PIE results also demonstrated that an intact $\mathrm{ZrN}$ coating layer can effectively block the interdiffusion between the U-Mo particles and the Al matrix. Gas bubble morphology was investigated in the sample irradiated to a dose of $2.9 \times 10^{17}$ ions $/ \mathrm{cm}^{2}(\sim 1200 \mathrm{dpa})$. The size of SEM-observable gas bubble in U-Mo ranged from tens of nanometers to hundreds of nanometers. It is speculated that large bubbles formed through the interlinkage of small bubbles. Gas bubble population was much smaller in the FMI region, which indicates that the FMI region has poor gas retention capability. No gas bubble superlattice was observed thus far. The information obtained from this ion irradiation will help develop more complete understanding of the irradiation response of U-Mo/Al fuel and facilitate fuel system optimization.

\section{Acknowledgements}

The authors would like to thank KAERI for manufacturing the U-Mo powder and Mr. E. O'hare from ANL for fabricating the plates. The authors wish to thank Dr. Jerry Nolen, Dr. Shaofei Zhu, and Mr. Mathew Hendricks for their assistance in the ATLAS irradiation. This manuscript also benefited from the discussions with Dr. Jian Gan from Idaho National Laboratory and Dr. Jeff Rest (retired from ANL). The help of Carolyn Tomchik in editing the manuscript is gratefully acknowledged. This research used resources of ANL's ATLAS facility, which is a DOE Office of Science User Facility. The electron microscopy was accomplished at Argonne National Laboratory at the IVEM-Tandem Facility, a U.S. Department of Energy Facility funded by the DOE Office of Nuclear Energy, operated under Contract No. DE-AC02-06CH11357 by UChicago Argonne, LLC. This work was supported by the U.S. Department of Energy, Office of Global Threat Reduction (NA-21), National Nuclear Security Administration, under Contract No. DE-AC-02-06CH11357 between UChicago Argonne, LLC and the Department of Energy and Argonne strategic Laboratory Directed Research and Development (LDRD) program. This work made use of the EPIC facility (NUANCE Center-Northwestern University), which has received support from the MRSEC program (NSF DMR-1121262) at the Materials Research 
Center; the Nanoscale Science and Engineering Center (NSF EEC-0647560) at the International Institute for Nanotechnology; and the State of Illinois, through the International Institute for Nanotechnology. 


\section{References}

[1] J.L. Snelgrove, G.L. Hofman, M.K. Meyer, C.L. Trybus and T.C. Wiencek, Nucl. Eng. Des. 178 (1997) 119-126.

[2] G.L. Hofman, J.L. Snelgrove, in Materials Science and Technology - Vol 10A- Nuclear Materials, B.R.T. Frost (Ed.), VCH Publishers, 1994.

[3] K.H. Kim, D.B. Lee, C.K. Kim, G.L. Hofman and K.W. Park, J. Nucl. Mater. 245 (1997) 179-184.

[4] G.L. Hofman, M.K. Meyer, J.L. Snelgrove, M.L. Dietz, R.V. Strain, K-H. Kim, in: Proc. Int. Meeting on Reduced Enriched for Research and Test Reactors (RERTR), Budapest, Hungary, 1999.

[5] Y.S. Kim, G.L. Hofman, H.J. Ryu, J.M. Park, A.B. Robinson, D.M. Wachs, Nucl. Eng. Technol. 45 (2013) 1-12.

[6] G.L. Hofman, Y.S. Kim, J. Rest, M.R. Finlay, in: Trans. International Topical Meeting on Research Reactor Fuel Management (RRFM) 2006, Sofia, Bulgaria, 2006.

[7] D.D. Keiser, A.B. Robinson, D.E. Janney, J.F. Jue, in: Trans. RRFM 2008, Hamburg, Germany, 2008.

[8] A. Leenaers, S. Van den Berghe, F. Charollais, P. Lemoine, C. Jarousse, A. Röhrmoser, W. Petry, in: Proc. the $31^{\text {st }}$ Int. Meeting on Reduced Enrichment for Research and Test Reactors (RERTR), Beijing, China, 2009.

[9] J.M. Park, H.J. Ryu, Y.S. Lee, B.O. Yoo, Y.H. Jung, C.K. Kim, Y.S. Kim, in: Trans. International Topical Meeting on Research Reactor Fuel Management (RRFM) 2008, Hamburg, Germany, 2008.

[10] S. Dubois, J. Noirot, J. Gatt, M. Ripert, P. Lemoine, P. Boulcourt, in: Trans, International Topical Meeting on Research Reactor Fuel Management (RRFM) 2007, Lyon, France, 2007.

[11] A. Izhutov, V. Alexandrov, A. Novosyolov, V. Starkov, A. Sheldyakov, V. Shishin, V. Yakovlev, I. Dobrikova, A. Vatulin, V. Suprun, Ye. Katashov, V. Lukichev, in: Proc. the 31st Int. Meeting on Reduced Enrichment for Research and Test Reactors (RERTR), Beijing, China, 2009.

[12] S. Van den Berghe, P. Lemoine, Nucl. Eng. Technol. 46 (2014) 125-146.

[13] S. Van den Berghe, W. Van Renterghem, A. Leenaers, J. Nucl. Mater. 375 (2008) 340-346.

[14] J. Gan, D.D. Keiser Jr., D.M. Wachs, A.B. Robinson, B.D. Miller, T.R. Allen, J. Nucl. Mater. 396 (2-3) (2010) 234-239.

[15] P. Lemoine, D.M. Wachs, in: Proceedings of the International Conference on Research Reactors: Safe Management and Effective Utilization, Sydney, Australia, 2007.

[16] A. Leenaers, S. Van den Berghe, E. Koonen, C. Jarousse, F. Huet, M. Trotabas, M. Boyard, S. Guillot, L. Sannen, M. Verwerft, J. Nucl. Mater. 335 (2004) 39-47.

[17] F. Huet, J. Noirot, V. Marelle, S. Dubois, P. Boulcourt, P. Sacristan, S. Naury, P. Lemoine, in: Trans. International Topical Meeting on Research Reactor Fuel Management (RRFM) 2005, Budapest, Hungary, 2005.

[18] V. Popov, M. Khmelevsky, V. Lukichev, O.A. Golosov, in: Proc. the $9^{\text {th }}$ International Topical Meeting on Research Reactor Fuel Management (RRFM), Budapest, Hungary, 2005.

[19] D.D. Keiser, A.B. Robinson, J.F. Jue, P. Medvedev, D.M. Wachs, M.R. Finlay, J. Nucl. Mater, 393 (2) (2009) 311-320.

[20] Y.S. Kim, G. Hofman, A.B. Robinson, in: Proc. the $13^{\text {th }}$ International Topical Meeting on Research Reactor Fuel Management (RRFM), Vienna, Austria, 2009. 
[21] A. Leenaers, S. Van den Berghe, J. Van Eyken, E. Koonen, F. Charollais, P. Lemoine, Y. Calzavara, H. Guyon, C. Jarousse, D. Geslin, D. Wachs, D. Keiser, A. Robinson, G. Hofman, Y.S. Kim, J. Nucl. Mater. 441 (2013) 439-448.

[22] M. Ripert, S. Dubois, P. Boulcourt, S. Naury, P. Lemoine, in: Trans. International Topical Meeting on Research Reactor Fuel Management (RRFM) 2006, Sofia, Bulgaria, 2006.

[23] A. Leenaers, S. Van den Berghe, W. Van Renterghem, F. Charollais, P. Lemoine, C. Jarousse, A. Röhrmoser, W. Petry, J. Nucl. Mater. 412 (2011) 41-52.

[24] G.A. Birzhevoy, V.V. Popov, O.A. Golosov, V.V. Shushlebin, V.A. Rychkov, M.S. Lyutikova, in: Trans. International Topical Meeting on Research Reactor Fuel Management (RRFM) 2007, Lyon, France, 2007.

[25] A. Leenaers, S. Van den Berghe, C. Detavernier, J. Nucl. Mater. 440 (2013) 220-228.

[26] S. Van den Berghe, A. Leenaers, E. Koonen, L. Sannen, Adv. Sci. Tech. 73 (2010) 78-90.

[27] H.-Y. Chiang, R. Jungwirth, T. Zweifel, W. Schmid, W. Petry, F. Kraus, in: Proc. Int. Meeting on Reduced Enrichment for Research and Test Reactors (RERTR), Santiago, Chile, 2011.

[28] S. Van den Berghe, Y. Parthoens, G. Cornelis, A. Leenaers, E. Koonen, V. Kuzminov, C. Detavernier, J. Nucl. Mater. 442 (2013) 60-68.

[29] A. Leenaers, "Surface-engineered low-enriched Uranium-Molybdenum fuel for research reactors", PhD thesis 2014, University of Ghent - SCK•CEN, ISBN-9789076971223.

[30] A. Leenaers, S. Van den Berghe, E. Koonen, V. Kuzminov, C. Detavernier, Manuscript submitted for publication (2014).

[31] H. Palancher, N. Wieschalla, P. Martin, R. Tucoulou, C. Sabathier, W. Petry, J. Berar, C. Valot, S. Dubois, J. Nucl. Mater. 385 (2009) 449-455.

[32] H-Y. Chiang, T. Zweifel, H. Palancher, A. Bonnin, L. Beck, P. Weiser, M. Döblinger, C. Sabathier, R. Jungwirth, W. Petry, J. Nucl. Mater. 440 (2013) 117-123.

[33] J. Gan, D.D. Keiser Jr, B.D. Miller, D.M. Wachs, T.R. Allen, M. Kirk, J. Rest, J. Nucl. Mater. 411 (2011) 174-180.

[34] R.C. Birtcher, J.W. Richardson, M.H. Mueller, J. Nucl. Mater. 230 (1996) 158-163.

[35] N. Wieschalla, A. Bergmaier, P. Böni, K. Böning, G. Dollinger, R. Großmann, W. Petry, A. Röhrmoser, J. Schneider, J. Nucl. Mater. 357 (2006) 191-197.

[36] J. Ziegler, SRIM, 2010. http://www.SRIM.org

[37] K. Yasunaga, K. Yasuda, S. Matsumura, T. Sonoda, Nucl. Instrum. Meth. B 266 (2008) 28772881.

[38] C. Meis, A. Chartier, J. Nucl. Mater. 341 (2005) 25-30.

[39] A.E. Dwight, J. Nucl. Mater. 2 (1960) 81-87.

[40] E. Welcomme, H. Palancher, C. Sabathier, Ph. Martin, J. Allenou, C. Valot, F. Charollais, M.C. Anselmet, R. Jungwirth, W. Petry, L. Beck, C. Jarousse, R. Tucoulou, P. Lemoine, in: Proc. the $13^{\text {th }}$ International Topical Meeting on Research Reactor Fuel Management (RRFM), Vienna, Austria, 2009.

[41] N. Wieschalla, A. Bergmaier, P. Böni, K. Böning, G. Dollinger, R. Großmann, W. Petry, A. Röhrmoser, J. Schneider, J. Nucl. Mater. 357 (2006) 191-197.

[42] D.B. Butrymowicz, J.R. Manning, M.E. Read, J. Phys. Chem. Ref. Data, 2 (1973) 643-655. 
[43] F. Huet, V. Marelle, J. Noirot, P. Sacristan, P.Lemoine, in: Proc. the 25th Int. Meeting on Reduced Enrichment for Research and Test Reactors (RERTR), Chicago, USA, 2003.

[44] J.M. Hamy, P. Lemoine, F. Huet, B. Guigon, C. Jarousse, J.L. Emin, in: Proc. the $8^{\text {th }}$ International Topical Meeting on Research Reactor Fuel Management (RRFM), Munchen, Germany, 2004.

[45] Y.S. Kim, G.L. Hofman, H.J. Ryu, S.L. Hayes, J. Phase. Equilib. Diff. 27 (2006) 614-621.

[46] R. Jungwirth, T. Zweifel, H.-Y. Chiang, W. Petry, S. Van den Berghe, A. Leenaers, J. Nucl. Mater. 434 (2013) 296-302.

[47] Y.S. Kim, G. L. Hofman, J. Nucl. Mater. 425 (2012) 181-187.

[48] K.T. Conlon, D.F. Sears, in: Trans. International Topical Meeting on Research Reactor Fuel Management (RRFM), Sofia, Bulgaria, 2006.

[49] F. Mazaudier, C. Proye, F. Hodaj, J. Nucl. Mater. 377 (2008) 476-485.

[50] M. Mirandou, S. Balart, M. Ortiz, M. Granovsky, J. Nucl. Mater. 323 (2003) 29-35.

[51] E. Perez, D.D. Keiser Jr., Y.H. Sohn, Metall. Mater. Trans. A, 42A (2011) 3071-3083.

[52] H. Palancher, P. Martin, V. Nassif, R. Tucoulou, O. Proux, J.-L. Hazemann, O. Tougait, E. Lahéra, F. Mazaudier, C. Valot, S. Dubois, J. Appl. Crystallogr. 40 (2007) 1064-1075.

[53] H.J. Ryu, Y.S. Han, J.M. Park, S.D. Park, C.K. Kim, J. Nucl. Mater. 321 (2003) 210-220.

[54] H.J. Ryu, Y.S. Kim, G.L. Hofman, J. Nucl. Mater. 385 (2009) 623-628.

[55] H.J. Ryu, Y.S. Kim, G.L. Hofman, D.D. Keiser, in: Proc. the 28 ${ }^{\text {th }}$ Int. Meeting on Reduced Enrichment for Research and Test Reactors (RERTR), Cape Town, South Africa, 2006.

[56] D.R. Olander, Fundamental Aspects of Nuclear Reactor Fuel Elements, published by technical information center, Energy Res. Dev. Admin. 1 (1976). ISBN 0-87079-031-5.

[57] G.S. Was, Z. Jiao, E. Getto, K. Sun, A.M. Monterrosa, S.A. Maloy, O. Anderoglu, B.H. Sencer, M. Hackett, Scripta Mater. 88 (2014) 33-36.

[58] L.K. Mansur, Nucl. Technol. 40 (1978) 5-34.

[59] L.K. Mansur, J. Nucl. Mater. 78 (1978) 156-160. 
Figure captions

Figure 1. The backside view of the multi-specimen sample holder dedicated for ATLAS irradiation with 5 thermocouples connected.

Figure 2. Loading arrangement of specimens in the sample holder. Different color represents different dose rate, and each $2 \mathrm{~mm}$ in diameter circle indicates a mini-sample holder.

Figure 3. Ion range distribution (left scale) and energy deposition (right scale) inside (a) $\mathrm{Al}$ and (b) U-7wt\%Mo.

Figure 4. SEM images of U-Mo/Al dispersion fuels irradiated with $84 \mathrm{MeV}$ Xe to a dose of $2.6 \times 10^{17}$ ions $/ \mathrm{cm}^{2}((\mathrm{a})$ and (b)) and the as-fabricated specimens ((c) and (d)). (a) and (c) are the specimens that contain $\mathrm{ZrN}$-coated U-7wt\%Mo; and (b) and (d) contain bare U-7wt\%Mo powder.

Figure 5. SEM image showing the top view of the specimen irradiated with $84 \mathrm{MeV}$ Xe to a dose of $2.9 \times 10^{17} \mathrm{ions} / \mathrm{cm}^{2}$.

Figure 6. Electron diffraction patterns across the FMI area in the specimen irradiated with $84 \mathrm{MeV}$ Xe to a dose of $2.9 \times 10^{17}$ ions $/ \mathrm{cm}^{2}$, showing crystallinity.

Figure 7. TEM image showing details of the FMI area in the sample irradiated with $84 \mathrm{MeV}$ Xe to a dose of $2.9 \times 10^{17}$ ions $/ \mathrm{cm}^{2}$. The inset selected-area diffraction (SAD) pattern shows that the FMI area has a nano-crystalline structure.

Figure 8. U, Al and combined (Zr L $\alpha$ red, $\mathrm{Al} \mathrm{K \alpha}$ blue and U M $\alpha$ green) X-ray maps of ZrN-coated UMo particles irradiated with $84 \mathrm{MeV}$ Xe to a dose of $2.6 \times 10^{17}$ ions $/ \mathrm{cm}^{2}$.

Figure 9. SEM image showing the cross section through the irradiated surface of the ZrN-coated U$7 \mathrm{wt} \%$ Mo specimen irradiated with $84 \mathrm{MeV}$ Xe to a dose of $2.9 \times 10^{17} \mathrm{ions} / \mathrm{cm}^{2}$.

Figure 10. SEM micrographs of U-Mo fuel irradiated with $84 \mathrm{MeV}$ Xe to a dose of $2.9 \times 10^{17} \mathrm{ions} / \mathrm{cm}^{2}$ (a) shows the Xe bubble distribution range; (b) shows bubble morphology in U-Mo fuel irradiated with $84 \mathrm{MeV}$ Xe to a dose of $2.9 \times 10^{17}$ ions $/ \mathrm{cm}^{2}$; higher magnification (c) in U-Mo and (d) at the UMo and FMI interface.

Figure 11. TEM micrographs of intra-granular Xe gas bubbles in U-Mo observed in the sample irradiated with $84 \mathrm{MeV}$ Xe to a dose of $2.9 \times 10^{17}$ ions $/ \mathrm{cm}^{2}$ by going through (a) underfocus and (b) overfocus conditions. The inset SAD pattern shows that the images were taken near [111] zone.

Figure 12. Bright-field TEM micrographs of the FMI area in the sample irradiated with $84 \mathrm{MeV}$ Xe to a dose of $2.9 \times 10^{17}$ ions $/ \mathrm{cm}^{2}$ by going through (a) underfocus and (b) overfocus conditions. 


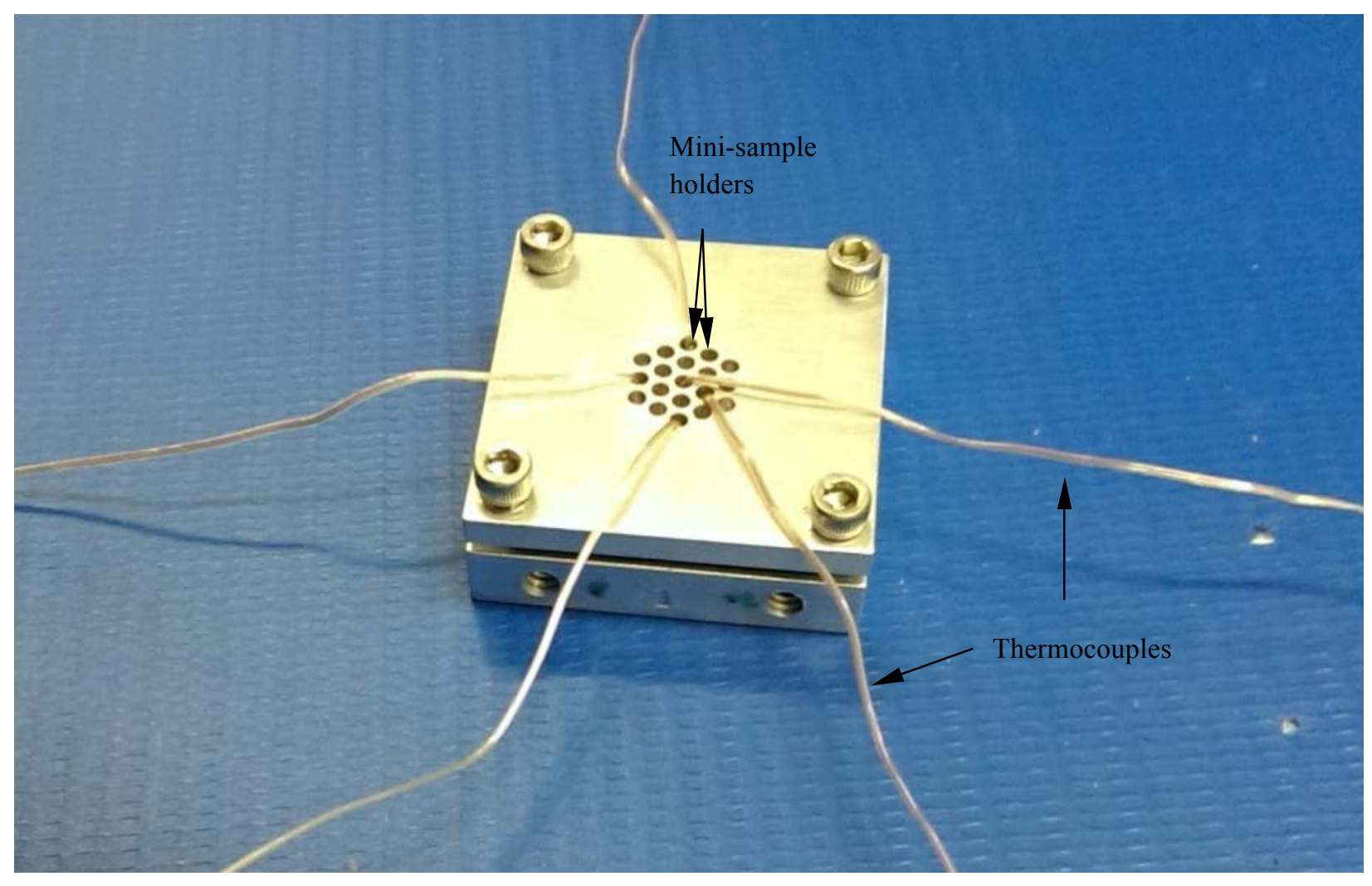

(Figure 1) 


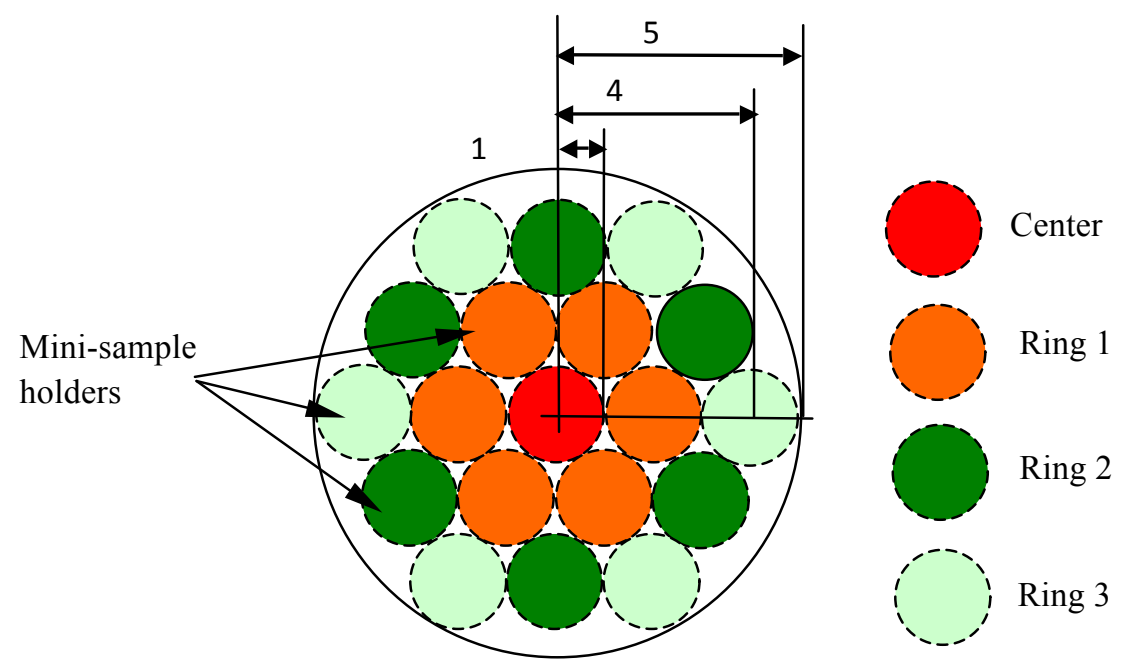

(Figure 2) 
(a) Aluminum

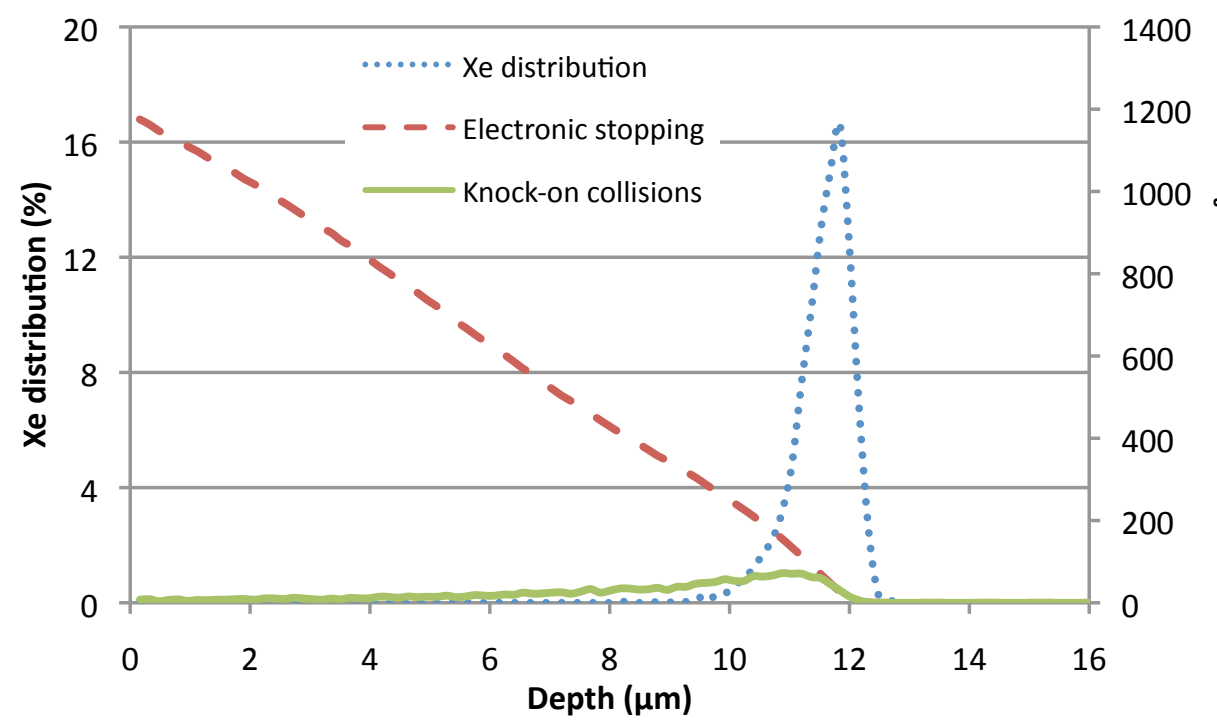

(b) U-7wt\%Mo

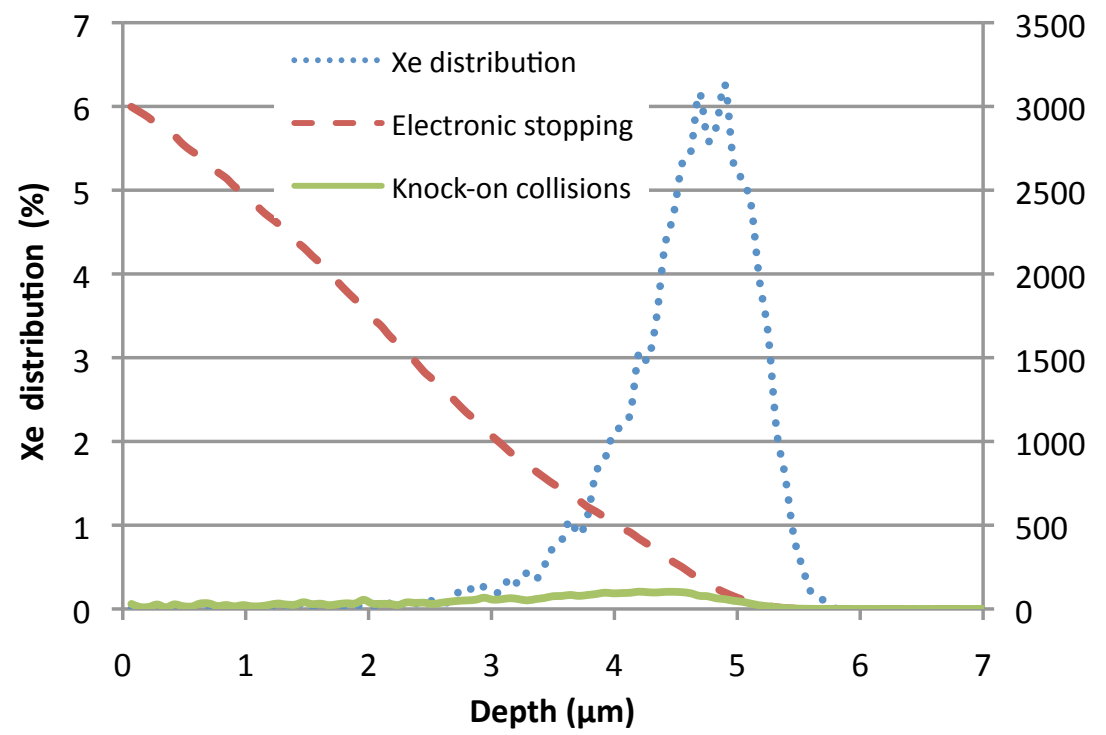

(Figure 3) 

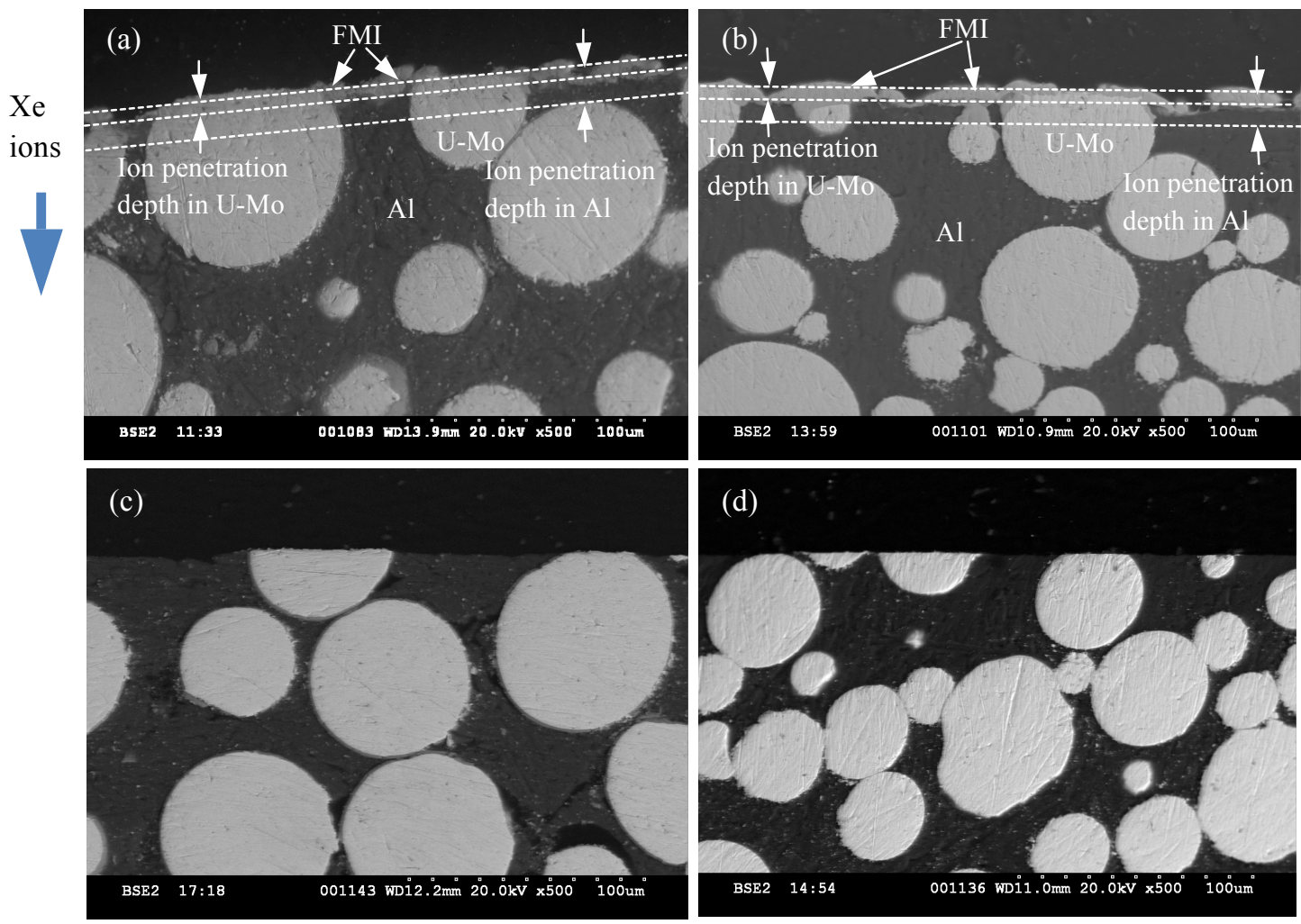

(Figure 4) 


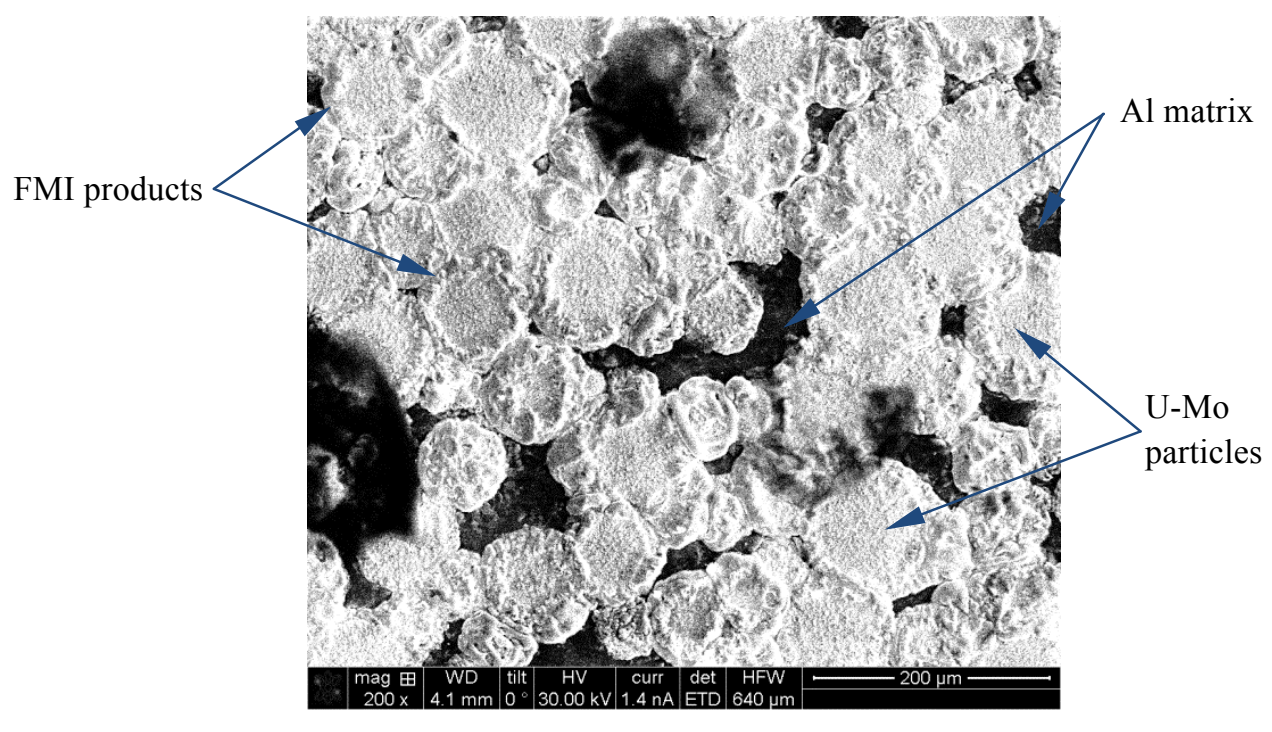

(Figure 5) 


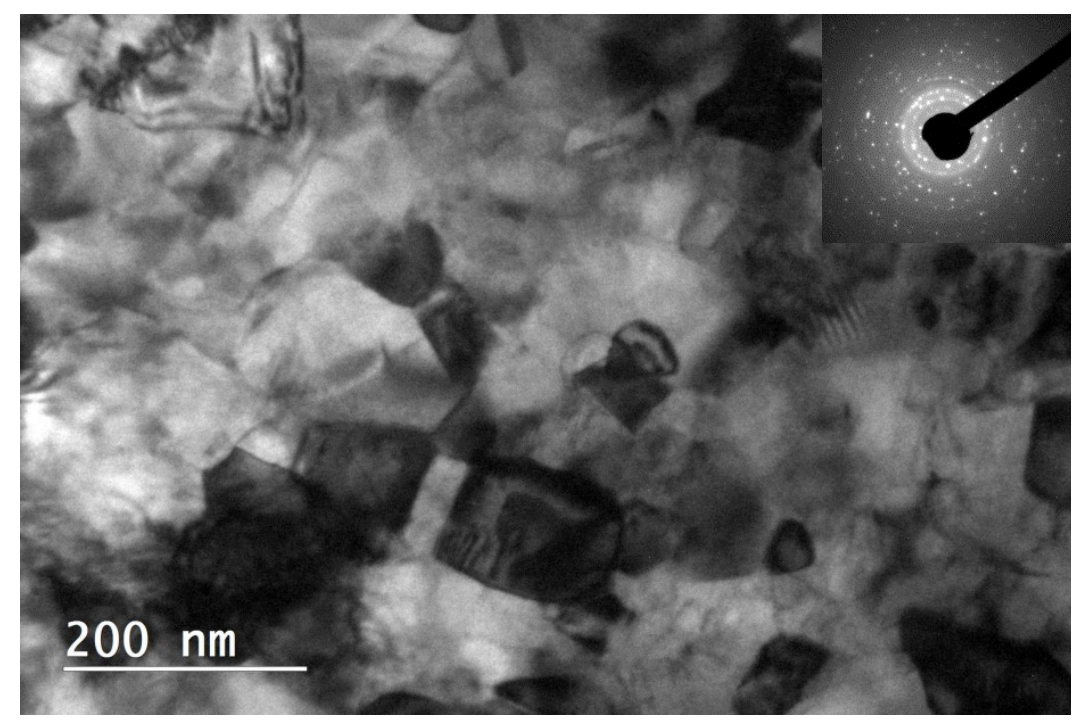

(Figure 6) 


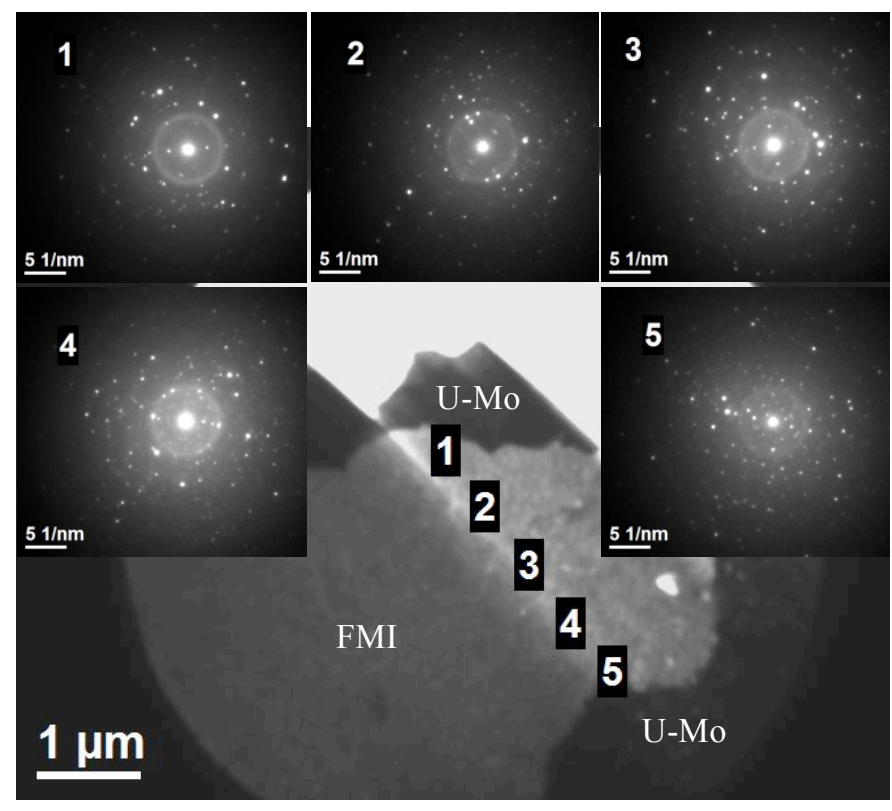

(Figure 7) 


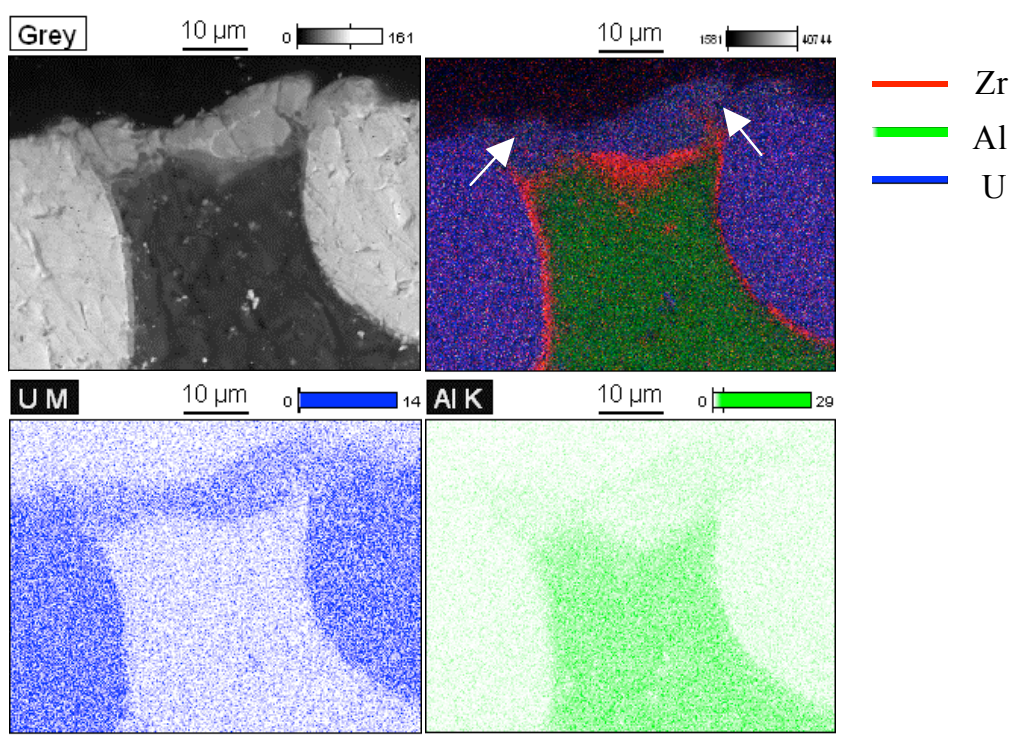

(Figure 8) 


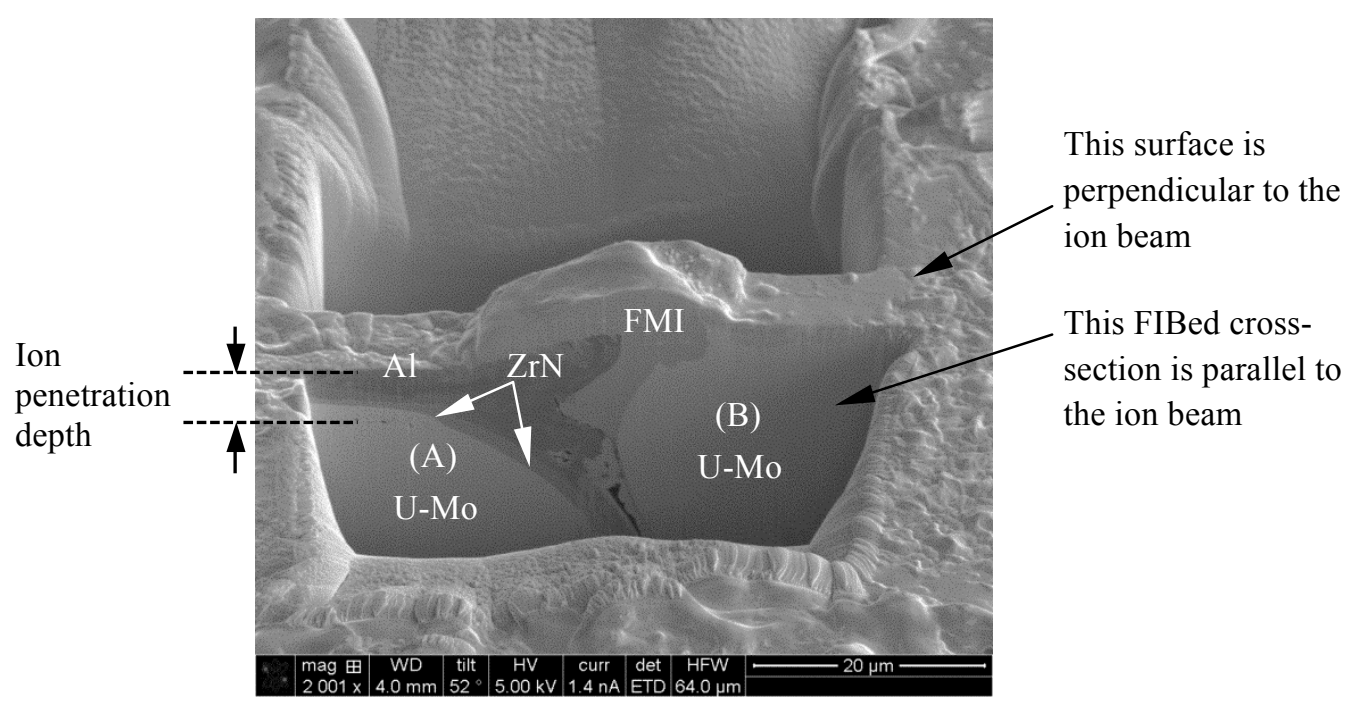

(Figure 9) 


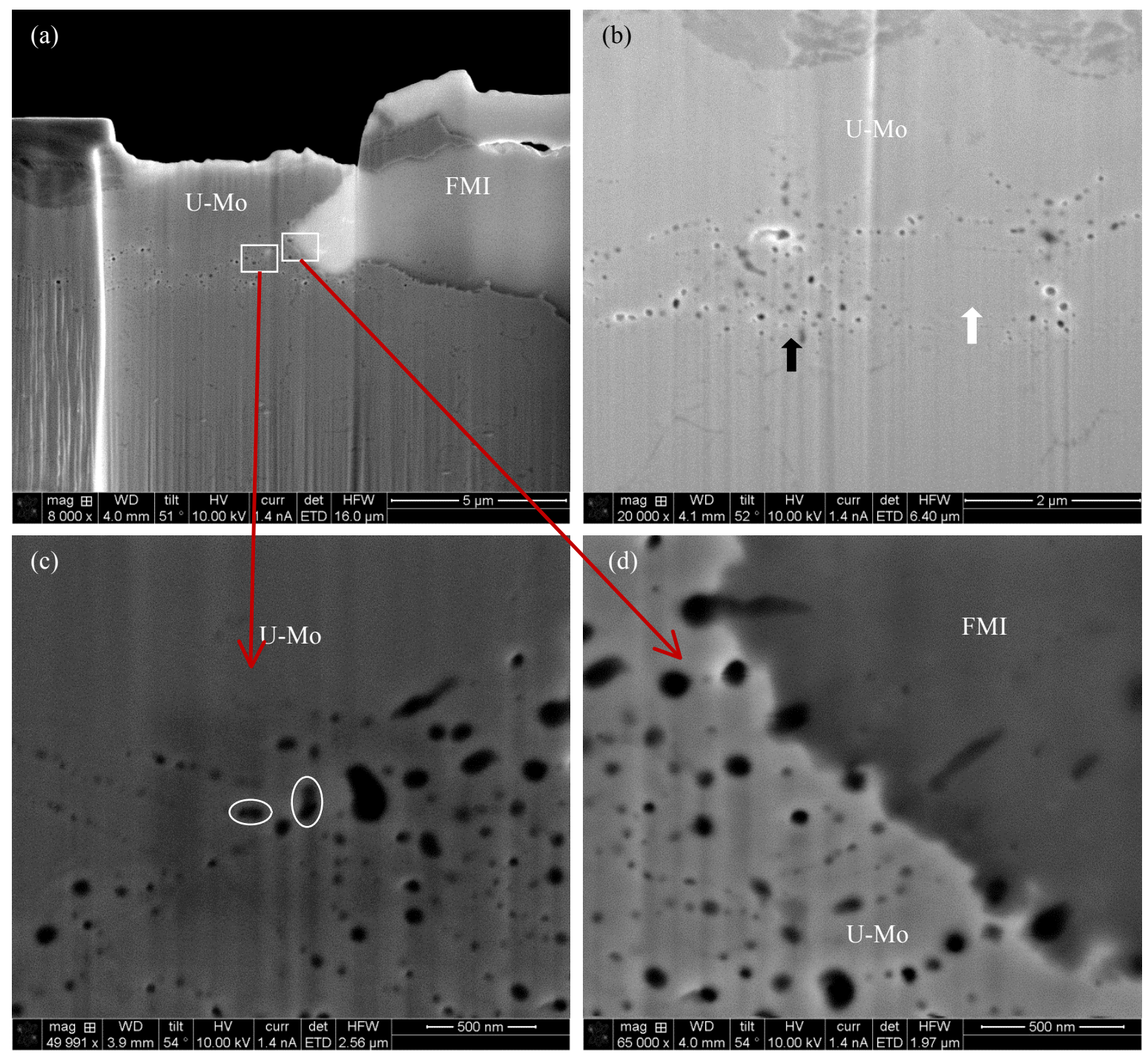

(Figure 10) 

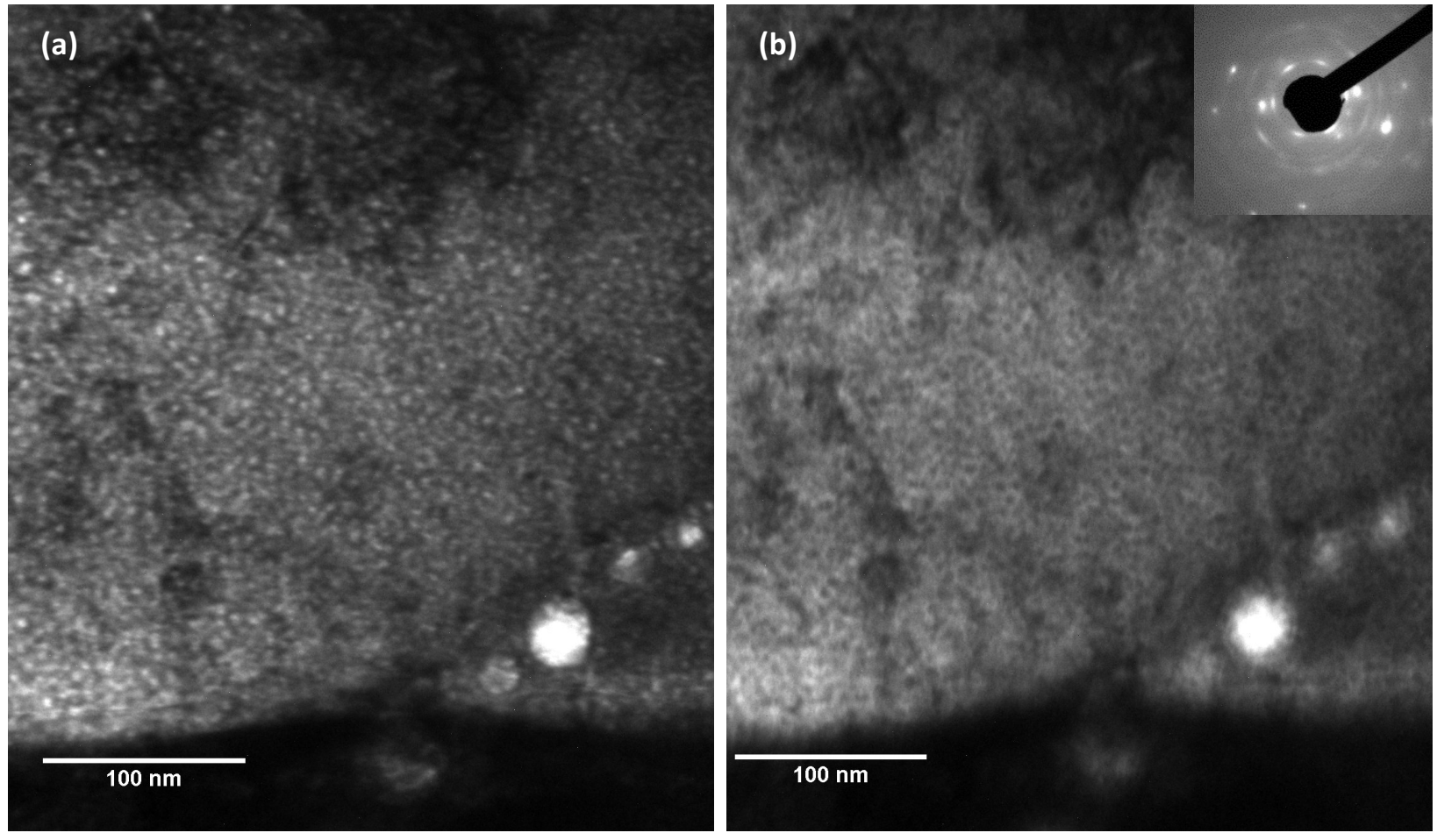

(Figure 11) 

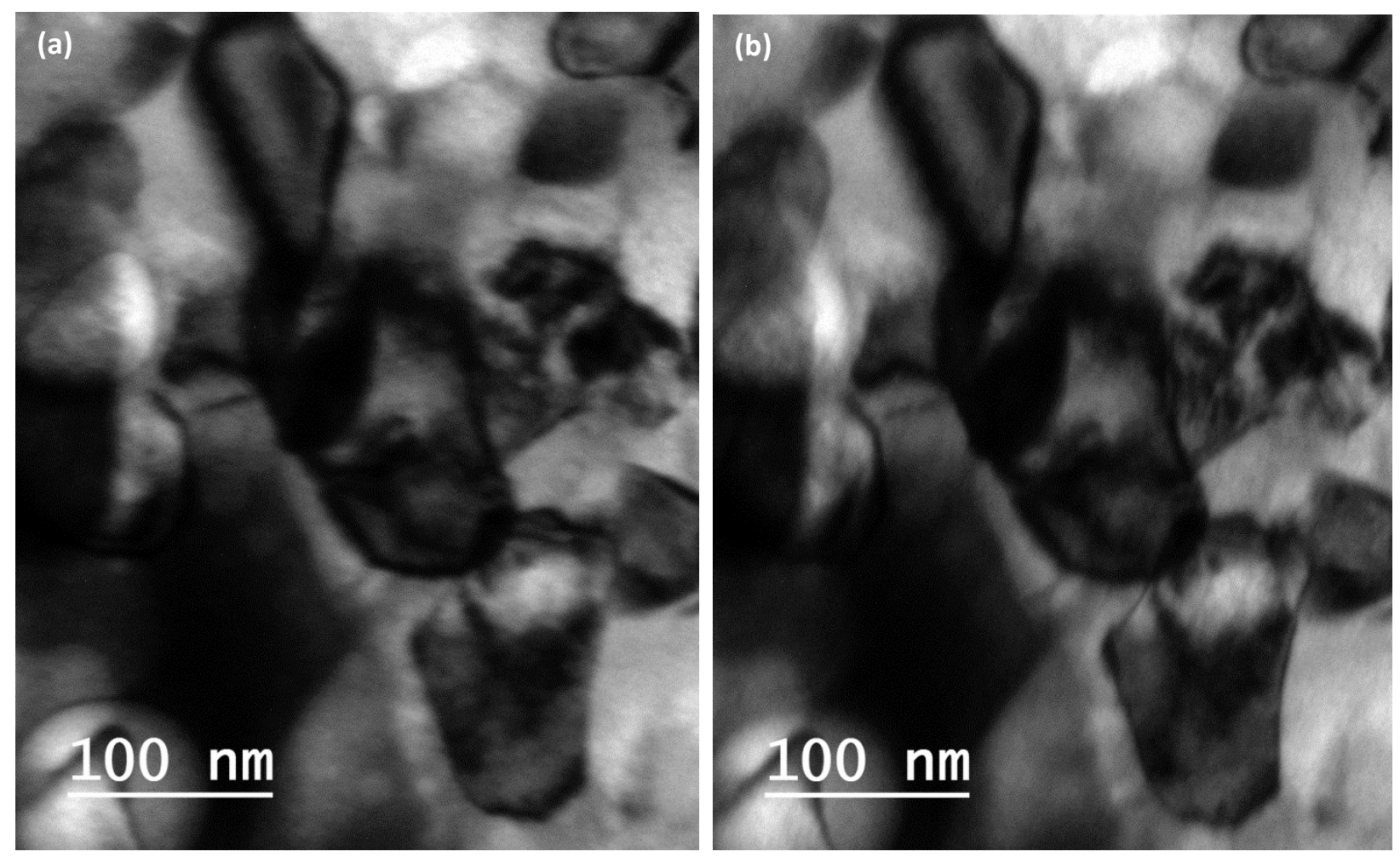

(Figure 12) 
Table 1 Calculated irradiation parameters for each U-7wt\%Mo specimen in the sample stage

\begin{tabular}{lllll}
\hline Location & $\begin{array}{l}\text { Fraction of total } \\
\text { current }\end{array}$ & $\begin{array}{l}\text { Average dose rate } \\
\left.\text { (ions } / \mathrm{cm}^{2} / \mathrm{s}\right)\end{array}$ & $\begin{array}{l}\text { Final dose } \\
\left.\text { (ions } / \mathrm{cm}^{2}\right)\end{array}$ & Peak dpa \\
\hline Center & 0.031 & $9.2 \times 10^{11}$ & $2.9 \times 10^{17}$ & 1206 \\
Ring 1 & 0.0276 & $8.2 \times 10^{11}$ & $2.6 \times 10^{17}$ & 1081 \\
Ring 2 & 0.0221 & $6.6 \times 10^{11}$ & $2.1 \times 10^{17}$ & 873 \\
Ring 3 & 0.0198 & $5.7 \times 10^{11}$ & $1.8 \times 10^{17}$ & 748 \\
\hline
\end{tabular}


Table 2 Measured composition of the FMI at several positions in various samples

\begin{tabular}{|c|c|c|c|c|}
\hline Examined sample & at. $\% \mathrm{Al}$ & at. $\%$ Mo & at.\% U & $\mathrm{X}$ in $(\mathrm{UMo}) \mathrm{Al}_{\mathrm{x}}$ \\
\hline \multicolumn{5}{|l|}{ This irradiation } \\
\hline Ring 1, ZrN-coated & 77.8 & 3.9 & 18.3 & 3.5 \\
\hline Ring 1, ZrN-coated & 78.7 & 4.0 & 17.3 & 3.7 \\
\hline Ring 1, ZrN-coated & 85.6 & 2.0 & 9.8 & 7.3 \\
\hline Ring 1, uncoated & 71.3 & 3.5 & 25.2 & 2.5 \\
\hline Ring 1 , uncoated & 82.4 & 2.4 & 15.2 & 4.7 \\
\hline Center, ZrN-coated & 79.7 & 4.3 & 16.0 & 3.9 \\
\hline \multicolumn{5}{|l|}{ FUTURE test [16] } \\
\hline$\left(<3 \times 10^{21} \mathrm{f} / \mathrm{cm}^{3}\right)$ & 76.7 & 4.6 & 18.7 & 3.3 \\
\hline & 82.5 & 3.0 & 14.5 & 4.7 \\
\hline \multicolumn{5}{|l|}{ IRIS-1 test [43] } \\
\hline$(\mathrm{BU}=61 \%)$ & & & & 6.0 \\
\hline$(\mathrm{BU}=67.5 \%)$ & & & & 7.0 \\
\hline
\end{tabular}

